\title{
A produção da diversidade sexual e de gênero nas práticas do CRAS
}

Priscila Pavan Detoni. Universidade Vale do Taquari

Paula Sandrine Machado. Universidade Federal do Rio Grande do Sul

Henrique Caetano Nardi. Universidade Federal do Rio Grande do Sul

\section{Resumo}

Este trabalho busca compreender como se produzem sujeitos, corpos e comportamentos por meio de atos performativos no interior dos dispositivos do gênero e da sexualidade nos serviços de um Centro de Referência de Assistência Social (CRAS). Para tanto, analisamos material etnográfico sobre como as práticas discursivas constituem as performatividades no tocante às expressões de gênero e sexualidade utilizando situações-problema pertinentes à diversidade sexual e de gênero em um CRAS, localizado em Porto Alegre, no Rio Grande do Sul, Brasil. Observamos que os/as técnicos/as sociais e os/as estagiários/as das áreas da Psicologia e do Serviço Social reconhecem a importância do CRAS enquanto porta de entrada para diferentes sujeitos e demandas, para além das famílias tradicionais e das mulheres cisgêneras. Entretanto, mesmo que a atenção às questões da assistência que são atravessadas pela diversidade sexual e de gênero seja uma preocupação neste serviço, tal tema urge ser inserido também nos processos de formação, assim como nas reuniões de rede e nas orientações da Política Nacional de Assistência Social (PNAS).

Palavras-chave: CRAS, performatividade, diversidade sexual e de gênero.

\section{Abstract}

Production in the sexual and gender diversity within the practices of CRAS. This research seeks to understand how the subjects, bodies, and behaviors are produced by performative roles within the gender and sexuality devices in the services offered at a Social Assistance Reference Center (CRAS). For this, we analyzed ethnographic material on how the discourse constitute the performativities regarding gender and sexual expressions making use of problematic situations pertinent to sexual and gender diversity in a CRAS, located in Porto Alegre, Rio Grande do Sul, Brazil. We observed that the social technician and psychology interns recognize the importance of the CRAS as an entry way for different subjects and demands beyond the traditional families and cisgender women. However, even though the attention to issues about social assistance which is crossed by sexual and gender diversity is a concern in this service. It needs, therefore, to also be present in the formation/training process, as well as in the meetings of the assistance network and in the guidelines of the National Social Assistance Policies (PNAS).

Keywords: CRAS, performativity, sexual and gender diversity.

\section{Resumen}

Producción de la diversidad sexual y de género en las prácticas del CRAS. El objetivo de este trabajo es comprender cómo se producen los sujetos, los cuerpos y los comportamientos a través de actos performativos dentro de los dispositivos de género y sexualidad en los servicios de un Centro de referencia de asistencia social (CRAS). Con este fin, analizamos material etnográfico sobre cómo las prácticas discursivas constituyen performatividades con respecto a las expresiones de género y sexualidad utilizando situaciones problemáticas pertinentes a la diversidad sexual y de género en un CRAS, ubicado en Porto Alegre, Rio Grande do Sul, Brasil. Observamos que los técnicos sociales y los aprendices en las áreas de Psicología y Trabajo Social reconocen la importancia de CRAS como una puerta de entrada a diferentes temas y demandas, además de las familias tradicionales y las mujeres cisgénero. Sin embargo, a pesar de que la atención a los problemas de la asistencia que atraviesan la diversidad sexual y de género sea una preocupación en este servicio, dicho problema debe incluirse en los procesos de capacitación, así como en las reuniones de la red y las pautas de la Política Nacional de Asistencia Social (PNAS).

Palabras clave: CRAS, performatividad, género y diversidad sexual. 
Esse trabalho busca compreender como se produzem sujeitos, corpos e comportamentos por meio de atos performativos no interior dos dispositivos de gênero e sexualidade nos serviços de um Centro de Referência de Assistência Social (CRAS). Para tanto, analisamos material etnográfico que indica como as práticas discursivas constituem performatividades ${ }^{1}$ no tocante às expressões de gênero e sexualidade. Partiremos de três situações-problema que remetem à diversidade sexual e de gênero em um CRAS, localizado em Porto Alegre, no Rio Grande do Sul, Brasil, as quais consideramos condensarem uma série de outras situações que ocorreram ao longo do trabalho de campo realizado entre 2014 e 2015.

No CRAS, unidade básica da Política Nacional de Assistência Social - PNAS, a diminuição da desigualdade de gênero, na maioria das vezes, fica adstrita à atenção às mulheres, como demonstram os estudos de Detoni, Machado e Nardi (2018), Meyer, Klein, Dal'Igna e Alvarenga (2014), Lago et al. (2012), Carloto e Mariano (2012) e Lisboa (2010). Tais estudos têm como ponto em comum uma perspectiva crítica em relação à feminização ${ }^{2}$ da política, com foco no cuidado das famílias, que têm como figura central as mulheres.

Ainda, é importante destacar que existem poucos estudos sobre a relação entre a Política Nacional de Assistência Social (PNAS) (2004) e a Política Nacional de Saúde Integral de Lésbicas, Gays, Bissexuais, Travestis e Transexuais (LGBT) (2011). Para L. Mello, Irineu, Froemming e Ribeiro (2013), as políticas públicas relativas a trabalho, assistência social e previdência social são minoritárias no campo das ações que pretendem assegurar direitos à população de Lésbicas, Gays, Bissexuais, Transexuais, Travestis, Transexuais e outras identidades como Intersexuais e queer ${ }^{3}$ (LGBT+) no Brasil.

A PNAS traz no seu texto a expressão "identidades estigmatizadas em termos étnico, cultural e sexual" na caracterização das vulnerabilidades dos/as usuários/as (Ministério do Desenvolvimento Social e Combate à Fome [MDS], 2004, p. 34). Além disso, essa política salienta que atende famílias e indivíduos. Nessas famílias, podem-se incluir configurações formadas por casais de pessoas homossexuais, com ou sem filhos/as, além de famílias monoparentais, onde a/o mãe/pai/filho/a pode ser travesti, transexual, gay, lésbica (L. Mello et al., 2013).

Contudo, em nenhum momento, a PNAS faz referência direta à diversidade sexual e de gênero, o que faz com que se reitere a categoria "gênero" como algo que remete às mulheres cisgêneras ${ }^{4}$, dificultando $a$ possibilidade de reconhecimento de LGBT+. Isso não significa que essa população não procure os serviços do Sistema Único de Assistência Social (SUAS) no CRAS, a sua porta de entrada, e não somente nos Centros de Referência Especializados em Assistência Social (CREAS LGBT) existem em poucas cidades brasileiras. Existem, portanto, escassas referências para orientar as ações dos/as técnicos/as sociais em relação a essa população.

A partir de uma etnografia realizada em um CRAS em Porto Alegre, o presente trabalho busca investigar de que forma a PNAS é performatizada nas práticas cotidianas desse serviço, sobretudo no que diz respeito à diversidade sexual e de gênero de pessoas LGBT+. Pela análise de três situações-problema, nas quais utilizaremos nomes fictícios para seus protagonistas - "Virginia, Leila e Thomas", descreveremos as histórias desses/as usuários/as no CRAS e como foram realizados os seus respectivos acolhimentos. Não buscamos uma linearidade nas histórias nem nas práticas desenvolvidas no serviço, e sim apresentar os enunciados ${ }^{6}$ que constituem os jogos de verdade a partir dos quais se pode falar (e de que forma) sobre os sujeitos e as instituições, sendo o ato enunciativo (que depende de uma posição de enunciação) entendido aqui como ato performativo.

\section{Atos performativos no interior dos dispositivos do gênero e da sexualidade}

Judith Butler $(2012,2013)$, inspirada pelos trabaIhos de Michel Foucault, traçou uma genealogia do gênero para explicar como os sujeitos são produzidos nas práticas de exclusão que não aparecem como sujeitos de direito na estrutura jurídica ou política tais como os designados corpos e sujeitos abjetos, os quais não correspondem à inteligibilidade de uma norma que pressupõe uma relação linear e única entre sexo-gênero-desejo.

Por isso, Butler (2013) indagou se o sexo é natural, anatômico, cromossômico ou hormonal, se tem uma história e qual seria sua gênese. De acordo com a autora, ser homem ou mulher não é da ordem de uma natureza anterior aos atos performativos. Ela argumenta que o sexo e o gênero são discursivamente construídos e que o sexo, portanto, constitui-se como um efeito naturalizado. Assim sendo, tanto o sexo quanto o gênero são efeitos de instituições, discursos e práticas (Salih, 2012). Desta forma, Butler (2004, 2013) assume a concepção de que o sujeito não é preexistente 
aos atos performativos, através dos quais as identidades são construídas e reconstruídas.

A identificação do sexo é possível, portanto, no interior de um dispositivo político que se constrói na lógica da reprodução e da hierarquia heterossexual (Butler, 2004, 2013). A performatividade do gênero pode ou não ter "sucesso" dentro da lógica heteronormativa. Este sucesso acontece quando o corpo, o gênero e a sexualidade correspondem às normas da heterossexualidade. A construção da "identidade social" define-se por um gênero que se torna inteligível a partir da norma da heterossexualidade compulsória, tomando a noção binária como parâmetro para a construção da identidade. A partir disso, Butler (2013) questionou a suposta linearidade naturalizada entre o sexo, o gênero e o desejo.

Todavia, nenhum sujeito consegue corresponder inteiramente à norma, como também não pode existir absolutamente fora dela, o que faz do gênero a estilização repetida nos corpos, através de atos repetidos que se cristalizam no interior de um quadro regulatório altamente rígido para parecer natural. Por isso, o gênero é sempre um fazer (Butler, 2013). Isso não significa negar a materialidade dos corpos, mas analisar de que forma as materialidades em relação ao gênero e à sexualidade são construídas na nossa sociedade, enquanto resultado do discurso e da lei (Salih, 2012).

De acordo com Butler (2013), o conceito de gênero foi produzido a partir da lógica da desigualdade, o que marca a generificação na linguagem, nos corpos, nos sujeitos. Da mesma forma que a PNAS busca diminuir a desigualdade de gênero, ela também pode reiterar as posições tradicionais de gênero e sexualidade, uma vez que os estudos têm apontado como população predominante nos serviços dos CRASs as mulheres cisgêneras com filhos/as. Tal efeito performativo emerge nas entrevistas realizadas com usuárias do CRAS pesquisado, onde duas delas referem que o público do CRAS seriam as "mães solteiras", ou seja, aquelas que se responsabilizam sozinhas pelos/as filhos/as ou são "abandonadas" pelos companheiros, e, outras cinco, que o serviço seria para "mães de família", isto é, se destinaria a auxiliar mulheres que cumprem o código moral que lhes atribui o cuidado de seus familiares.

Não por acaso, a principal atividade atribuída pelos programas sociais para mulheres de baixa renda ainda está ligada à maternidade, ao espaço doméstico e familiar, o que produz uma naturalização das desigualdades de gênero, bem como das noções sociais de corpo, comportamentos e espaços femininos e masculinos
(Detoni et al, 2018; Meyer, Klein, \& Fernandes, 2012). Contudo, o CRAS é um espaço que recebe uma enorme diversidade de sujeitos e demandas. E quando essa diversidade se refere à sexualidade, ao gênero ou ao corpo sexuado, ela ganha contornos particulares no serviço. Por isso, no próximo bloco, apresentaremos situações-problema que indicam as complexidades dessa questão.

\section{Corpus da pesquisa etnográfica: situações-problema}

Durante uma reunião no CRAS com os serviços conveniados, depois de cinco meses de inserção da pesquisadora no campo indagando sobre a temática das relações de gênero e sexualidade guiada pelo método etnográfico (Fonseca, 1998; Souza, 2015), foi agendada pelos profissionais do serviço uma discussão de "casos" que tangenciavam a diversidade ${ }^{7}$ nas relações de gênero e sexualidade. Nesta discussão, emergiram importantes debates acerca de como lidar com tais situações. Utilizaremos três dos "casos" - assim denominados pela equipe - para analisarmos as práticas do CRAS no que se refere à diversidade em relação às expressões do gênero e da sexualidade.

\section{Virginia: uma Criança Referida como Hermafrodita e/ou de Sexo Ambíguo}

O primeiro caso descrito por uma técnica social ${ }^{8}$ foi o de uma "menina hermafrodita", conforme termo utilizado por ela, para quem atribuiremos o nome fictício de Virginia.

Virginia era cuidada pela avó, que era atendida no Serviço de Proteção de Atenção Integral à Família (PAIF) ${ }^{9}$, e era designada como menina pela família. $\mathrm{Na}$ época em que foi acompanhada pelo CRAS, ela deveria ter cerca de 8 anos de idade, era uma Pessoa Com Deficiência ( $P C D)$, segundo denominação da política, e que, através da assistência social, tinha encaminhado o seu Benefício de Prestação Continuada (BPC) ${ }^{10}$. Virginia havia ficado sob a guarda da avó porque supostamente sofrera abusos sexuais por parte de um tio. Seu encaminhamento ocorreu via Conselho Tutelar (CT), conforme parâmetros do Estatuto da Criança e do Adolescente ECA (Lei 8.069/90), e teve o apoio do PAIF.

A técnica social do PAIF relatou, na reunião, que a avó e a menina foram atendidas diversas vezes por diferentes equipes da saúde - tanto nas Unidades Básicas de Saúde (UBSs) como em hospitais próximos, as quais trouxeram a possibilidade de fazer uma 
cirurgia "corretiva" na genitália da criança. Contudo, a avó achava que não tinha necessidade de cirurgia porque, para ela, ser "PCD" impossibilitaria uma vida sexual para a neta. As reações dos/as técnicos/as, assistentes sociais e psicólogos/as, durante esta reunião, indicavam concordância com a decisão da avó, a qual Ihes parecia prudente, uma vez que também não vislumbravam um futuro sexual para a criança e porque avaliavam que a "correção" genital poderia ser complexa ${ }^{11}$.

Segundo A. G. Mello e Nuernberg (2012), em nossa sociedade, a primeira questão em relação a um corpo dito deficiente diz respeito à sua suposta vulnerabilidade, fator que sequer permite cogitar uma sexualidade, segundo os padrões da norma que regula quem teria capacidade ou não de exercê-la. Assim, a mulher com deficiência é vista primeiramente a partir do marcador da diferença da deficiência, ao qual Virginia responde. Para os casos de deficiência, a dimensão do cuidado é pensada como direito básico, faltando, no entanto, serem também exploradas questões como a política da aparência, a medicalização do corpo e da subjetividade, bem como a construção social da identidade (A. G. Mello \& Nuernberg, 2012). Isso se materializa nessa intervenção do CRAS em relação à criança intersexual com PCD, situação em que o enunciado que se refere à deficiência de Virgínia se sobrepõe àquele relativo à sua sexualidade.

O foco das ações do CRAS se voltou para o acompanhamento desta família, sendo que a equipe identificava a avó como cuidadora e protetora. Foi avaliado e possibilitado o acesso aos benefícios sociais, como o BPC e passagens de ônibus fornecidas pela assistência social para os tratamentos de saúde. Virginia, quando chegou ao PAIF, já estava inscrita em uma inteligibilidade de gênero. Era reconhecida como menina pela família, e não com o termo da "intersexualidade" ou do conceito médico mais recente "Desordens/ Anomalias do Desenvolvimento Sexual" ${ }^{12}$, que não eram conhecidos por todos/as os/as técnicos/as, muitos dos quais usavam o termo "sexo ambíguo" e hermafrodita. Porém, havia conhecimento no CRAS de que cirurgias para pessoas trans e intersex eram realizadas no Hospital de Clínicas de Porto Alegre (HCPA) ${ }^{13}$.

O sexo nos designa enquanto humanos, e essa "humanidade sexuada" - na forma binária, é naturalizada dentro dos atos performativos dos dispositivos do gênero e da sexualidade. A performatividade do gênero coloca a construção das relações de gêneros, corpos e comportamentos em ato. Por isso, precisamos repetir e reiterar os atos para (nos) designar e existir dentro de um determinado sexo, que deve corresponder a um certo gênero. Mesmo transgredindo as normas de um gênero, nunca estaremos completamente fora dele, porque precisamos estar inscritos no sistema da generificação para podermos ser reconhecidas/os como humanos/cidadãs-cidadãos, necessitamos ter um registro civil e um corpo inteligível.

Esta situação-problema nos auxilia a pensar nas dificuldades do CRAS em lidar com outras situações que escapam daquilo que se considera a norma em relação ao corpo. Mesmo que considerados "algo" atípico no serviço, a forma de lidar com estes sujeitos faz com que sejam acionados mecanismos tradicionais da assistência social, aliados aos encaminhamentos aos serviços de saúde, como se a intersexualidade não fizesse parte da discussão da PNAS enquanto uma questão de direitos. Ao mesmo tempo, ao se alinharem com o argumento da avó acerca da impossibilidade sexual para o corpo intersex, os/as profissionais estavam produzindo uma materialidade para o corpo da menina, um corpo abjeto/interditado para a prática sexual, sob o véu da vulnerabilidade.

O corpo abjeto pode ser entendido como uma quimera, ou um corpo que não está dentro de uma inteligibilidade binária - o que vai além da não congruência entre corpo, sexo, gênero e desejo, como no caso das pessoas trans e intersex (Butler, 2012). O sistema de produção de sujeitos da abjeção ancora-se na repulsa do corpo deficiente, ou do corpo que não está inscrito naquilo que é habitual, como também na negação da sexualidade e do prazer na vida das pessoas PCDs e nas interdições que fazem parte da sexualidade LGBT+.

Da mesma forma que Machado (2008) infere sobre o saber médico na construção de corpos sexuados via processos de saber-poder, percebemos o controle exercido nas práticas do CRAS ao enunciar os corpos e os sujeitos também enquanto foco de investimento de saber-poder, lugar este ocupado pelos/as técnicos/ as sociais das áreas da Psicologia e do Serviço Social na construção de sujeitos generificados. Portanto, conforme Machado (2014), é necessário refletir sobre o sujeito político do feminismo que vem sendo interpelado pela diversidade sexual e pela intersexualidade, para eticamente considerar as múltiplas intersexualidades que existem no jogo das relações de poder e na produção biopolítica dos corpos, porque o reconhecimento fora da norma binária opositora implica na produção de um lugar de abjeção. 
O campo dos estudos feministas e de gênero tem avançado na medida em que se articula com outras categorias de análise - os marcadores sociais da diferença, tais como geração, classe, raça, etnia, orientação sexual, região e religião (Collins, 2016; Piscitelli, 2009). Uma questão, contudo, permanece à revelia do esforço de interseção dessas categorias, a saber, a deficiência (A. G. Mello \& Nuernberg, 2012).

Há, portanto, uma dificuldade de se estabelecer uma transversalidade entre gênero, sexualidade e deficiência, uma vez que a deficiência não se encerra no corpo, mas é um processo social e cultural. O sujeito é efeito em vez de causa. Nosso reconhecimento depende da relação com os outros. Para que possamos conceituar nosso corpo, há que se levar em conta e repensar gênero, incapacidades físicas e racialização - nomeações que têm obedecido no campo das políticas públicas à reprodução de normas corporais.

Nesta intersecção, como conciliar o cuidado da pessoa intersex com deficiência com o exercício da sua sexualidade? Os estudos feministas e queer ${ }^{14}$ têm composto esse campo de reivindicações para além dos padrões hegemônicos funcionais e corporais, pautando a questão da existência e do cuidado como questão de justiça, além de tensionar o sistema binário sexo-gênero. Afinal, a norma para pensar o corpo deficiente acaba por se enquadrar no sistema de classificação e produção de sujeitos marcado pela assimetria e pela desigualdade (A. G. Mello \& Nuernberg, 2012). Para produzir um pensamento feminista negro capaz de refletir um ponto de vista em relação a si mesma, à família e à sociedade, Collins (2016) descreve a possibilidade de beneficiar os estudos acadêmicos e sociológicos, caso se deposite confiança nas próprias biografias pessoais e culturais como das mulheres e LGBT+ com deficiências poderiam prover, e não partir dos discursos biologistas que por vezes, ficaram na égide do homem médio, branco, europeu, heterossexual.

\section{Leila: uma Mulher Trans de Meia Idade}

Outro "caso" trazido na reunião como uma situação problema por uma técnica social foi a história de uma usuária do CRAS, Leila, que ora se designava como travesti, ora como transexual, e que era trabalhadora do sexo. Leila era atendida no CRAS desde que o serviço abriu, há cerca de cinco anos. Sua demanda mais recente para o serviço é de que precisava de maior ajuda de benefícios do CRAS, porque estava mais velha, na faixa etária dos 50 anos, e não conseguia mais se manter no mercado da prostituição. Ela se mantinha com a ajuda de um filho, jovem adulto, que trabalhava no mesmo ramo, além de contar com valor básico de 77 reais do Programa Bolsa Família (PBF).

As técnicas sociais contam que já atenderam várias vezes Leila e o filho, e estes apresentaram diferentes demandas: moradia, saneamento, alimentação, dificuldade de acesso aos serviços da saúde, além de brigas familiares entre eles. Relatam que existe uma vinculação de Leila e seu filho com o serviço, pois sempre que têm alguma necessidade, buscam pelo atendimento do CRAS, onde recebem acolhimento e escuta.

Além disso, nessa reunião, a equipe relatou que Leila sonhava em fazer a cirurgia de redesignação sexual e a alteração do nome masculino para o feminino, mas achava que não poderia mais fazer esta cirurgia por já estar muito velha. A equipe também referiu que, em certos momentos, com o apoio dos/as trabalhadores/as do CRAS, ela até pensou em buscar o HCPA para poder tomar hormônios com acompanhamento especializado e, quiçá, fazer cirurgia, mas acabara por se achar com muita idade para encarar todo esse processo, já tendo, afinal, se aceitado como era. Contudo, o nome masculino nos documentos ainda a incomodava.

Para os/as técnicos/as, a troca de nome estava condicionada à troca de sexo, não tendo estes aventado a possibilidade de que a mudança de nome poderia se dar sem a necessidade da redesignação sexual por via cirúrgica. Assim, embora no RS exista uma política pública que permite a feitura de carteira de identidade valendo-se exclusivamente do nome social ${ }^{15}$, sendo suficiente que a pessoa que se identifique com um determinado gênero que tenha acesso à carteira de nome social ${ }^{16} \mathrm{e}$ passe a utilizar, no registro de identificação, o nome com o qual ela se reconhece, e embora haja precedentes para que travestis e transexuais possam requerer a retificação do registro civil sem a realização de redesignação sexual cirúrgica (Guaranha, 2014), essa discussão parece não ter chegado aos técnicos/as do CRAS.

Assim, conforme aponta Guaranha (2014), embora uma política pública - como a criação da carteira de nome social no RS - possa ter sido concebida de forma a contemplar a diversidade das experiências de gênero e sexualidade, não necessariamente esta chegará à população destinatária da maneira como foi planejada, uma vez que pode haver fragilidade na implementação das ações desta política, não sendo replicada no nível micropolítico que se dá no encontro entre trabalhador e usuário do serviço. O uso do nome social no SUS foi reconhecido de forma institucional a partir 
do lançamento, pelo Ministério da Saúde, da Carta dos Direitos dos Usuários da Saúde, onde o cartão do SUS contempla o nome social (MDS, 2007). Entretanto, o mesmo ainda não tinha ocorrido com o Número de Inscrição Social (NIS) e com o cartão do Programa Bolsa Família (PBF), o que representa uma fragmentação entre as políticas públicas que teoricamente deveriam atuar de forma intersetorial. O nome social, por ter sido alçado a uma das bandeiras do movimento nacional de travestis e transexuais, foi uma das questões que mais obteve avanços no SUS para essa população nos últimos anos, conforme salientado por Guaranha (2014). Não obstante, ainda há impasses para ser aceito em certas instituições, sejam elas ou não da área da saúde.

Identificamos que a população LGBT acessa os serviços do CRAS por meio de acolhidas, inscrições no Cadastro Único, acompanhamento familiar e recebimento de benefícios sociais - como Leila, que é chamada pelo seu nome social, tem Cadúnico, e recebe o beneficio do PBF (por não ter renda fixa e estar em situação de vulnerabilidade social). Entretanto, persiste o desconhecimento sobre a existência de políticas públicas e serviços da rede de serviços do município e do Estado especialmente voltados para a população trans por parte de trabalhadores/as do CRAS. Há, ainda, falta de conhecimento sobre algumas intervenções realizadas pelos serviços de saúde, como o processo transexualizador (Ministério da Saúde [MS], 2013), e sobre outros serviços dirigidos à população LGBT (MS, 2011).

Os/as técnicos/as sociais do CRAS identificam como a maior vulnerabilidade de Leila a questão da prostituição, agravada pelo envelhecimento, que em tese torna mais difícil o exercício do trabalho. A equipe do CRAS, a partir desta situação-problema, refere dificuldades semelhantes em relação a outras mulheres transexuais e travestis ali acolhidas, resultantes da baixa escolarização das jovens, o que acaba as sujeitando à prostituição, avaliada por esta equipe como uma condição vulnerável, dentre outras fragilidades como a violência de gênero nos espaços urbanos e domésticos. Segundo a Associação Nacional de Travestis e Transexuais (ANTRA), um dos grandes problemas para a comunidade de travestis reside no fato de $90 \%$ de seu total ser de trabalhadoras do sexo, não contando com os benefícios da previdência social provenientes do trabalho formal e com fatores de trabalho precarizado e explorado - qual é o caso de Leila.

$\mathrm{Na}$ análise da construção de Leila enquanto sujeito, as interseccionalidades do gênero, da classe social, da profissão e de geração ganham destaque. Tanto que, na reunião em questão, os/as técnicos/as sociais e estagiários/as trouxeram à tona tais marcadores sociais da diferença, além de destacarem a importância desta temática ser incluída nos currículos da formação nas áreas tanto do Serviço Social quanto da Psicologia.

Condições como gênero, raça, etnia e classe não são perturbadoras em si mesmas, mas marcadores sociais das experiências de opressão, de abjeção e presentes nos processos de subjetivação. Nesse contexto, estudiosos/as do tema da transexualidade identificaram que o marcador social que se mostrou mais problemático é a baixa escolaridade, a qual aparece associada às dificuldades de acessar o mercado formal de trabalho. Igualmente, as manifestações de preconceito levam muitas/os transexuais a se tornarem profissionais do sexo, apesar de existirem diversas experiências de vida e de escolaridade entre as pessoas trans (Almeida \& Murta, 2013; Bento, 2011).

Podemos então, na fronteira entre o corpo e suas inscrições internas e externas, ver que o gênero é marcado performativamente através da produção disciplinar binária fixada no feminino e no masculino, o que faz com que pessoas trans sofram preconceitos e isso impacte na sua baixa escolaridade e vulnerabilidades ligadas a produção de estigmas. Este é o caso de Leila, que tem sua trajetória configurada como a de ser "abjeto" (Butler, 2012) para determinados (e vários) postos de trabalho - inclusive na prostituição, onde seu corpo, inclusive, não está mais dentro da faixa etária desejada.

\section{Thomas: um Jovem que Perdeu o Emprego por ter "Jeito Afeminado"}

$\mathrm{Na}$ discussão de situações-problema sobre as práticas em relação ao gênero e à sexualidade no CRAS, uma das técnicas sociais comunicou que fez o atendimento de um jovem, Thomas, que relatou ter sido demitido de seu trabalho em um restaurante pelo fato de ser homossexual e parecer "afeminado". A técnica do CRAS interviu junto a Thomas para que este buscasse outros espaços de trabalho. Apesar disso, ele relatou ter sentido dúvidas quanto à orientação prestada pela técnica em relação aos seus direitos.

Inclusive, na reunião de discussões, levantou-se a possibilidade de se processar ou não o antigo empregador do jovem, para demonstrar um posicionamento de luta contra esta forma de preconceito. Posicionamento este que também se traduz em uma forma de garantir alguns direitos em defesa dos quais as práticas do CRAS devem se apropriar para poderem proporcionar soluções 
cotidianas mais eficazes para problemáticas como essas as quais não são comuns de serem trazidas nos acolhimentos, mas que acontecem em especial nos atendimentos particularizados do CRAS, onde os/as usuários/as se sentem mais protegidos para discutirem suas questões.

Dentro das práticas do CRAS, ainda foi trazido para o debate da reunião que umas das orientações para Thomas deveria ser o encaminhamento para a defensoria pública, ou para universidades que prestam assistência jurídica, a fim de que Thomas pudesse reivindicar seus direitos em relação à homofobia sofrida.

A homofobia faz parte do cenário social (Butler, 2013). Esta prática (da homofobia) é considerada para a população LGBT+ uma atitude de hostilidade, rejeição irracional, ou mesmo ódio contra os homossexuais. Mas não apenas isso: trata-se de uma manifestação que qualifica o outro como contrário, inferior ou anormal, colocando-o de fora do universo comum dos humanos. Para o enfrentamento da homofobia, bem como das outras formas de LGBTfobia, incluindo a lesbofobia e a transfobia, os movimentos LGBT+ vêm ao longo dos últimos anos buscando a legitimidade de seus direitos (MDS, 2004, 2011), apesar dos recentes retrocessos em todas as esferas das políticas públicas, especialmente voltadas para a diversidade.

Ainda na discussão deste "caso", uma das técnicas sociais trouxe a seguinte fala: "Filho homossexual é bom para a mãe. Ajuda em casa e ainda pode impor respeito para a comunidade se não for tão afeminado". Uma das usuárias entrevistadas, no mesmo sentido, disse que tinha dois filhos: um supostamente heterossexual e outro homossexual. O primeiro tinha sido vítima de uma chacina e quase chegou a morrer, fato que a levou a buscar o CRAS para pedir ajuda e passagens para cuidar dele em outro território, a fim de evitar que ele fosse morto pelo tráfico. Inclusive, ela relatou que apareceu no jornal o que tinha acontecido e o nome do filho dela. Quanto ao outro, apenas mencionou: "Ele é homossexual, mas ninguém é perfeito! Eu trato bem, e aqui [no CRAS] ele é bem tratado."

Se, de um lado, existe o preconceito, a dificuldade de se manter em certos postos de trabalho - efeitos da homofobia, os quais muitas vezes levam os jovens ao desemprego; de outro, a homossexualidade já começa a ser vista como fator de proteção e autocuidado dentro das comunidades atendidas (pelo CRAS pesquisado), uma vez que esse sujeito não reproduza as violências de uma masculinidade tóxica que dizima a juventude de jovens negros nas periferias, dentro de uma lógica de eficácia da virilidade, seja pelos números de homicídios e suicídios (Baère $\&$ Zanello, 2018). Por isso, geralmente, os filhos homossexuais são vistos pelos/as técnicos/as como aqueles que melhor cuidam das suas mães e famílias, não se envolvendo tão diretamente no tráfico e nas outras formas de violência urbana.

Ainda nessa discussão, um dos estagiários do CRAS mencionou que, durante as entrevistas para entrar no estágio, posicionara-se mais masculinizado do que é, para não parecer afeminado e assim poder ocupar o posto de estágio pretendido no CRAS. Só depois de inserido no estágio é que pode observar se o espaço dava ou não possibilidade para que o sujeito saísse do armário (Sedgwick, 2007). Ele identificou então que esse CRAS era um local que apresentava uma diversidade de trabalhadores/as, com diferentes expressões de gênero e sexualidade, e que isso lhe auxiliou a sair do armário - sensibilizando, por conseguinte, seu olhar para questões como a homofobia, apesar dos déficits sentidos nessa área pela formação acadêmica no curso de Serviço Social.

Essa diversidade, embora existente no CRAS, não deixa de inscrever seus/suas trabalhadores/as em uma lógica que os determina fora da heteronormatividade, o que fica evidente na fala de um deles: "Eu que sou do ramo [gay] não sei o que fazer com muitas situações". Identificamos que a discussão sobre a diversidade sexual e de gênero ainda está no armário relativamente às práticas desenvolvidas no CRAS e na PNAS.

Para Sedgwick (2007), os sujeitos homossexuais acabam sendo articulados conforme cada situação com novos esquemas e demandas de sigilo ou de exposição da sua expressão da sexualidade. A vida social da população LGBT+, regrada pela presença do armário, pode ser melhor entendida como o armário servindo de proteção para a não exposição em todos os momentos, e também como escudo em situações de violência de modo que a pessoa se faça enquadrar na norma e/ou padrão vigente.

Percebe-se, portanto, a forte presença de uma (ainda) vigente hegemonia heterossexual, a qual contém a homossexualidade no armário em determinados espaços - como é o caso de Thomas (que não pode vivê-la no espaço de trabalho) e de outros jovens usuários da comunidade que precisam manter uma fachada. Na situação de Thomas, não se acionaram ferramentas de enfrentamento à homofobia, mas se investe na sugestão de troca de emprego do jovem 
demitido por ser "afeminado", o que pode significar a manutenção deste armário.

A homossexualidade pode ser vista também como um desvio da norma de gênero - das inscrições dentro de uma ou outra expressão do gênero. Segundo Butler (2013):

A replicação de construtos heterossexuais em estruturas não heterossexuais salienta o status cabalmente construído do chamado assim heterossesxual original. Assim, o gay é para o hetero não que uma cópia é para o original, mas em vez disso, o que é uma cópia para uma cópia (p. 57).

Ao ser sexuado, o sujeito é submetido a um conjunto de regulações sociais, formadoras do sexo, do gênero, dos prazeres, e dos desejos. Além disso, tal conjunto se interpõe enquanto princípio hermenêutico de auto-interpretação (Butler, 2013) - como nas situações-problema apresentadas, onde o gênero é produzido com significação opressiva, principalmente para as mulheres e para a população LGBT+.

\section{Considerações finais}

O fio que conduz estes "casos", ou situações-problema, destacados pela equipe do CRAS, é o fato de este mesmo CRAS possibilitar o acolhimento de diversos sujeitos - reiterando ou transgredindo práticas, através da performatividade. Por isso, faz-se mister evidenciar de que modo se constituem os atos performativos, para que esses sujeitos e corpos possam ter possibilidade de existência e de garantia de direitos.

As formas de reiteração do gênero e da sexualidade fazem-se evidenciar na conformação dos corpos dentro da norma binária heterossexual e cisgênera: no corpo da criança intersex, que por ser PCD não tem reconhecida a possibilidade de ser "cirurgiada" ou de vivenciar sua sexualidade; no caso da usuária "trans", que desejava passar pelo processo transexualizador e pela troca de nome, mas acreditava já ter alcançado idade muito avançada para tal, e não obteve informações apropriadas sobre esses processos por conta do desconhecimento sobre as possibilidades para os cuidados em saúde destinados à população LGBT (MS, 2011) e para a retificação do registro civil e/ ou obtenção da carteira de nome social (o que seria um direito seu e evitaria constrangimentos).

Na PNAS é recente a inclusão do nome social no Cadúnico (em 2016), pós a realização dessa pesquisa de campo, o que denota o reconhecimento da população $\mathrm{LGBT}+$, principalmente de pessoas transexuais, travestis e transgêneros. Apesar da existência, ainda mais constituída na retórica do que na prática, de espaços especializados para o atendimento da população LGBT+ na PNAS como os CREASs LGBT, os CRASs ainda desempenham uma função importante no primeiro acesso para vários/as usuários/as e suas famílias, que precisam ser referenciados para outras políticas públicas, tendo-se o conhecimento de que poucas cidades possuem essas unidades de CREASs, sendo Porto Alegre - RS, uma delas.

Os CRASs, apesar de sucateados pelas atuais políticas sociais e econômicas perversas, ainda são uma importante porta de entrada para todo um sistema de garantia de direitos, sua ação carece de discussões e orientações para a construção de práticas e prescrições inclusivas associadas aos regramentos de gênero e sexualidade, conforme já preconizadas no âmbito da PNAS - mas que requerem efetiva operacionalização no cotidiano de serviços dos CRASs.

Isso remete à "orientação" prestada para o jovem homossexual, que não repercutiu no enfrentamento direto à homofobia, qual posteriormente problematizado na discussão coletiva da equipe do CRAS - podem produzir diferenças em encaminhamentos futuros para situações semelhantes, uma vez que a pesquisa etnográfica não visa à neutralidade, e sim à mobilização dos sujeitos através da relação de alteridade estabelecida no campo (Eckert \& Rocha, 2008) pela posicionalidade (Haraway, 1995) teórica e corporal da própria pesquisadora. Por isso, Haraway (1995) destaca que: "Precisamos do poder das teorias críticas modernas sobre como significados e corpos são construídos, não para negar significados e corpos, mas para viver em significados e corpos que tenham a possibilidade de um futuro" (p. 16).

O que nos convoca a analisar que, apesar da falta de ferramentas para receber pessoas inscritas na diversidade sexual e de gênero, observamos que tanto os/ as técnicos/as quanto os/as estagiários/as das áreas da Psicologia e Serviço Social reconhecem a potência do trabalho no CRAS, que pode explorar um olhar abrangente para a complexidade de vulnerabilidades existentes, além dos aspectos familiares e na capacidade de se sustentar economicamente.

Identificamos, outrossim, que esses/as profissionais entram em consenso no que diz respeito à necessidade de debate nos processos de formação e nas orientações da própria PNAS relativamente aos marcadores sociais da diferença, de forma que o acolhimento dos sujeitos não dependa unicamente da capacidade empática de cada trabalhador/a no contato com o/a usuário/a para escuta

Estudos de Psicologia, 24(3), julho a setembro de 2019, 281-291 
cuidadosa, mas (e talvez principalmente) da inserção de formas de enfrentamento das LGBTsfobias - por via da intersetorialidade ${ }^{17}$ entre as políticas públicas.

Entretanto, importante fazer constar que no CRAS pesquisado existia uma atenção para estes sujeitos inscritos na diversidade sexual e de gênero, que reconheciam esse serviço por se sentirem acolhidos/as, como sujeitos de direitos, e não deslegitimados em razão de suas expressões de sexualidade e de gênero. Percebeu-se que existia uma preocupação genuína da equipe do CRAS, apesar da falta de preparo teórico acadêmico para acolher pessoas no avesso da norma cisgênero. Afinal, a PNAS precisa de maior investimento de forma ampla, bem como (re)conectar suas ações com as dos movimentos sociais e políticas públicas, como foram os programas que visibilizaram esses direitos - Programa Brasil Sem Homofobia (PBSH) (2004), o Plano Nacional de Promoção dos Direitos Humanos LGBT (2010), o Programa Nacional de Direitos Humanos 3 (PNDH 3) (Secretaria de Direitos Humanos da Presidência da República, 2009), e o Relatório de Monitoramento das Ações do Plano Nacional de Promoção da Cidadania e Direitos Humanos de Lésbicas, Gays, Bissexuais, Travestis e Transexuais (Secretaria de Direitos Humanos da Presidência da República, 2011). Por isso, o combate à discriminação pela expressão do gênero e da sexualidade precisam resistir e existir nos espaços públicos, de maneira a viabilizar a erradicação das LTBGfobias e as todas as segregações que fazem sujeitos menos humanos que outros.

\section{Referências}

Almeida, G., \& Murta, D. (2013). Reflexões sobre a possibilidade da despatologização da transexualidade e a necessidade da assistência integral à saúde de transexuais no Brasil. Sexualidad, Salud y Sociedad, (14), 380-407. doi: 10.1590/S1984-64872013000200017

Baére, F., \& Zanello, V. (2018). O gênero no comportamento suicida: uma leitura epidemiológica dos dados do Distrito Federal. Estudos de Psicologia, 23(2), 168-178. doi: 10.22491/1678-4669.20180017

Bento, B. (2011). Na escola se aprende que a diferença faz a diferença. Revista Estudos Feministas, 19(2), 549-559. doi: 10.1590/ S0104-026X2011000200016

Butler, J. (2004). Undoing gender. Nova lorque: Routedge.

Butler, J. (2012). Cuerpos que importan: sobre los límites materiales y discursivos del "sexo". Buenos Aires: Paidós.

Butler, J. (2013). Problemas de gênero. Rio de Janeiro: Civilização Brasileira.

Carloto, C. M., \& Mariano, S. A. (2012). Empoderamento, trabalho e cuidados: mulheres no programa bolsa família. Textos \& Contextos, 11(2), 258-272. Recuperado de http://revistaseletronicas.pucrs.br/ ojs/index.php/fass/article/viewFile/12337/8636
Collins, P. H. (2016). Aprendendo com a outsider within: a significação sociológica do pensamento feminista negro. Sociedade e Estado, 31(1), 99-127. doi: 10.1590/S0102-69922016000100006

Corrêa, S. O., \& Muntarbhorn, V. (Orgs.). (2006). Princípios de Yogyakarta: princípios sobre a aplicação da legislação internacional de direitos humanos em relação à orientação sexual e identidade de gênero. Yogyakarta: Autor. Recuperado de http://www.clam.org.br/uploads/ conteudo/principios_de_yogyakarta.pdf

Detoni, P. P., Machado, P. S., \& Nardi, H. C. (2018). "Em nome da mãe": performatividades e feminizações em um CRAS. Revista Estudos Feministas, 26(1), e45084. Epub Janeiro 15, 2018. doi: 10.1590/1806-9584.2018v26n145084

Eckert, C., \& Rocha, A. L. C. (2008). Etnografia: saberes e práticas. Revista lluminuras, 9(21), 1-23. Recuperado de http://seer.ufrgs.br/ index.php/iluminuras/article/ view/9301/5371

Fonseca, C. (1998). Quando cada não é um caso. Pesquisa Etnográfica e educação. Trabalho apresentado na XXI Reunião da ANPED, Caxambu, setembro de 1998.

Decreto n. 49.122 (2012, 17 de maio). (2012) Institui a Carteira de Nome social para Travestis e Transexuais no Estado do Rio Grande do Sul. Porto Alegre, RS: Governo do Estado do Rio Grande do Sul.

Foucault, M. (2005). Arqueologia do Saber (7 $7^{\mathrm{a}}$ ed., Tradução Luiz F.B. Neves). Rio de Janeiro: Forense Universitária, 2005.

Guaranha, C. (2014). O desafio da equidade e da integralidade: travestilidades e transexualidades no Sistema Único de Saúde. (Dissertação de Mestrado, Universidade Federal do Rio Grande do Sul, Porto Alegre). Recuperado de http://hdl.handle.net/10183/115052

Haraway, D. (1995). Saberes localizados: a questão da ciência para o feminismo e o privilégio da perspectiva parcial. Cadernos Pagu, (5), 7-41. Recuperado de https://periodicos.sbu.unicamp.br/ojs/index. php/cadpagu/article/view/1773

http://www.clam.org.br/pdf/principios_de_yogyakarta.pdf

Jesus, J. G. (2012). Orientações sobre identidade de gênero: conceitos e termos. Brasília: UFG. Recuperado de http://www.diversidadesexual. com.br/wp-content/ uploads/2013/04/G\%C3\%8ANEROCONCEITOS-E-TERMOS.pdf

Lago, M. C. S. , Silva, E. F., Freitas, R. C. M, Martins, A. P., Figueiredo, A. P., Dallmann, ... Verzola, Y. E. (2012). Táticas locais e estratégias internacionais: a política social do Programa Bolsa Família e as relações de classe, gênero, raça/etnia em Santa Catarina (o caso de Florianópolis). Relatório de Pesquisa, Florianópolis/UFSC, 2012.

Lei n. 8.069, de 13 de julho de 1990 (1990, 13 de julho). Dispõe sobre o Estatuto da Criança e do Adolescente e dá outras providências. Diário Oficial da União, seção 1. Brasília, DF. Recuperado de http:// www.planalto.gov.br/ccivil_03/LEIS/L8069.htm

Lisboa, T. K. (2010). Gênero, feminismo e serviço social - encontros e desencontros ao longo da história da profissão. Revista Kátalysis, 13(1), 66-75. Recuperado de http://www.scielo.br/pdf/rk/v13n1/08.pdf

Louro, G. L. (2001). Teoria queer - uma política pós-identitária para a educação. Revista Estudos Feministas, 9(2), 541-553. Recuperado de http://www.scielo.br/pdf/ref/v9n2/8639.pdf

Louro, G. L. (2007). O "estranhamento" queer. comunicação apresentada no Fazendo Gênero/ 2006 Simpósio temático: "A violência material e simbólica" Labrys: Estudos Feministas, 11. Recuperado de https:// www.labrys.net.br/labrys 11/libre/guacira.htm

Machado, P. S. (2008). Intersexualidade e o "Consenso de Chicago" as vicissitudes da nomenclatura e suas implicações regulatórias. Revista Brasileira de Ciências Sociais, 23(68), 109-123. doi: 10.1590/ S0102-69092008000300008

Machado, P. S. (2014). (Des)fazer corpo, (re)fazer teoria: um balanço da produção acadêmica nas ciências humanas e sociais sobre 
intersexualidade e sua articulação com a produção latino-americana. Cadernos Pagu, 14, 141-158. doi: 10.1590/0104-8333201400420141

Mello, A. G., \& Nuernberg, A. H. (2012). Gênero e deficiência: interseções e perspectivas. Revista Estudos Feministas, 20(3), 635-655. doi: $10.1590 /$ S0104-026X2012000300003

Mello, L., Irineu, B. A., Froemming, C. N., \& Ribeiro, V. K. (2013). Políticas públicas de trabalho, assistência social e previdência social para população LGBT no Brasil: sobre desejos, realizações e impasses. Revista de Ciências Sociais, 44(1), 132-160. Recuperado de http:// www.rcs.ufc.br/edicoes/v44n1/rcs_v44n1a6.pdf

Meyer, D. E., Klein, C., Dal'Igna, M. C., \& Alvarenga, L. F. (2014). Vulnerabilidade, gênero e políticas sociais: a feminização da inclusão social. Revista Estudos Feministas, 22(3), 885-904. doi: 10.1590/ S0104-026X2014000300009

Meyer, D. E., Klein, C., \& Fernandes, L. P. (2012). Noções de família em políticas de 'inclusão social' no Brasil contemporâneo. Revista Estudos Feministas, 20(2), 433-449. doi: 10.1590/S0104-026X2012000200005

Ministério da Saúde - MS. (2004). Brasil sem homofobia: programa de combate à violência e à discriminação contra GLTB e de promoção da cidadania homossexual. Brasília: Autor.

Ministério da Saúde - MS. (2007). Carta dos direitos dos usuários da saúde. Brasília: Autor.

Ministério da Saúde - MS. (2011). Política Nacional de Saúde Integral de Lésbicas, Gays, Bissexuais, Travestis e Transexuais. Brasília: Autor.

Ministério da Saúde - MS. (2013). Portaria n. 2.803, de 19 de Novembro de 2013. Redefine e amplia o Processo Transexualizador no Sistema Único de Saúde (SUS). Brasília, DF: Autor.

Ministério do Desenvolvimento Social e Combate à Fome - MDS. (2004). Política Nacional de Assistência Social -PNAS/2004. Brasília: Autor. Recuperado de

http://www.mds.gov.br/webarquivos/publicacao/assistencia_social/ Normativas/PNAS2004.pdf

Ministério do Desenvolvimento Social e Combate à Fome - MDS. (2006). Norma Operacional Básica de Recursos Humanos do SUAS. Brasília: Autor. Recuperado de http://www.mds.gov.br/suas/publicacoes>
Ministério do Desenvolvimento Social e do Combate à Fome - MDS. (2007) Cartilha de avaliação de pessoas com deficiência para acesso do beneficio de prestação continuada da assistência social. Brasília: Autor

Ministério do Desenvolvimento Social e do Combate à Fome - MDS. (2012). Caderno de orientações do serviço de proteção e atendimento integral à família (PAIF). Brasília: Autor.

Nascimento, S. (2010). Reflexões sobre a intersetorialidade entre as políticas públicas. Serviço Social \& Sociedade, (101), 95-120. doi: 10.1590/S0101-66282010000100006

Piscitelli, A. G. (2009). Gênero: a história de um conceito. In H. B. Almeida \& J.Szwako, (Orgs.), Diferenças, igualdade (pp. 116-148). São Paulo: Berlendis e Vertecchia.

Prefeitura Municipal de Porto Alegre (2013). Secretaria Municipal de Saúde. Portaria n. 1.113 de 03 de setembro de 2013. Dispõe sobre o reconhecimento e uso do nome social de pessoas travestis e transexuais em todas as unidades municipais de saúde e dá outras providências. Porto Alegre, RS. Recuperado de https://legislacaosirel. portoalegre.rs.gov.br/norma/2768

Salih, S. (2012). Judith Butler e a teoria queer. Belo Horizonte: Autêntica.

Secretaria de Direitos Humanos da Presidência da República. (2009). Programa Nacional de Direitos Humanos (PNDH-3). Brasília: Autor.

Secretaria de Direitos Humanos da Presidência da República. (2011). Relatório de Monitoramento das Ações do Plano Nacional de Promoção da Cidadania e Direitos Humanos de Lésbicas, Gays, Bissexuais, Travestis e Transexuais ? PNPCDH-LGBT. Brasília: Autor

Sedgwick, E. K. (2007). A epistemologia do armário. Cadernos Pagu,(28), 19-54. Recuperado de http://www.scielo.br/pdf/cpa/n28/03.pdf

Souza, M. R. (2015). Psicologia social e etnografia: histórico e possibilidades de contato. Psicologia: Ciência e Profissão, 35(2), 389-405. doi: 10.1590/1982-370301742013

Yannoulas, S. C. (2011). Feminização ou feminilização? Apontamentos em torno de uma categoria. Temporalis, 2(22), 271-292. Recuperado de http://periodicos.ufes.br/temporalis/article/view/1368

1. Performatividades destacadas como fundantes das produções de sujeitos, corpos e comportamentos na construção do gênero e da sexualidade, que acontece em ato e reiteradamente (Butler, 2013), o que será melhor explicado ao longo do artigo.

2. O conceito de feminização diz respeito ao ato de feminilizar-se, ou seja, de adquirir atribuições semelhantes às atribuições femininas no que respeita ao caráter analítico de um processo qualitativo que abrange esta categoria em movimento, em construção (Yannoulas, 2011).

3.Podemos entender a performatividade queer como movimento e teoria, que põe em questão os processos de normatização levados a efeito por grupos identitários de gênero, sexualidade e raça historicamente submetidos - o que permite compreendê-lo como um movimento pós-identitário. Mais do que uma nova posição de sujeito ou um lugar social estabelecido, queer indica a não-acomodação, admite a ambiguidade, o não-lugar, o trânsito, o estar-entre, o borramento de fronteiras (Louro, 2001, 2007).

${ }^{4}$ Ao utilizar o termo mulheres cisgêneras estamos nos referindo às mulheres que não são pessoas trans, uma vez que o conceito cisgênero abarca as pessoas que se identificam com o gênero que lhes foi determinado no momento de seu nascimento, ou seja, as pessoas não-transgêneras (Jesus, 2012). Esta marca do cisgênero faz um posicionamento dos corpos naturalizados, uma vez que os corpos trans sempre são marcados.

5. A demanda dos CREAS LGBT foi aprovada como proposta da I Conferência Nacional LGBT. De uma maneira geral, as ativistas entrevistadas pela equipe de Luiz Mello sinalizam que têm sido crescentes as possibilidades de diálogo entre o movimento LGBT e as secretarias de assistência social, com vistas ao atendimento "qualificado" de suas demandas nos CREAS, incluindo a criação de CREAS específicos para a população LGBT (Mello et al., 2013).

${ }^{6 .}$ Conforme Foucault (2005) todo enunciado ou sequência de enunciados é, pois, linguisticamente descritível como uma série de pontos de deriva possíveis, oferecendo um lugar a interpretação dentro de uma formação discursiva, o que possibilita a análise do discurso.

7." "Diversidade" pode ser pensada, nesse contexto, como corpos que estão no avesso da matriz normativa de gênero, ou seja, não inscritos na lógica binária do feminino e do masculino, e/ou que não respondem à heterossexualidade obrigatória.

8. Técnicos Sociais: são os/as profissionais que atuam na PNAS. A equipe mínima de um CRAS com equipe ampliada, segundo a Norma Operacional Básica de Recursos Humanos do SUAS (MDS, 2006), conforme prescrição para cada 5.000 famílias, é composta por quatro técnicos/as com nível 
superior (dois/duas assistentes sociais, um/a psicólogo/a, e um/a outro/a técnico/a, conforme diretriz do SUAS), mais quatro trabalhadores/as com nível médio, e um/a coordenador/a - também com nível superior. Contudo, essas equipes nem sempre apresentam esse quadro de profissionais, porque os serviços e a própria política ainda se encontram em um momento de implantação e organização.

9. O Serviço de Proteção e Atendimento Integral à Família (PAIF) é um dos serviços centrais do CRAS, balizador de suas atividades e do acompanhamento ao usuário e à família, juntamente com o Serviço de Convivência e Fortalecimento de Vínculos - SCFV, e o Serviço de Proteção Social Básica no Domicílio para Pessoas com Deficiência e Idosas (Ministério do Desenvolvimento Social e Combate à Fome [MDS], 2004). O PAIF teve suas raízes no início dos anos 2000, e passou a responder pela garantia do fortalecimento familiar e comunitário, na Proteção Social Básica - PPSB do SUAS, com vistas à superação, de modo integrado, das fragilidades sociais (MDS, 2012).

10. O Benefício de Prestação Continuada (BPC) para Pessoas com Deficiência (PCDs) garante um salário mínimo às pessoas com deficiência que comprovem não possuir meios de prover a própria manutenção e nem a ter provida por sua família, de acordo com o seguinte critério: ter renda familiar mensal per capita inferior a $1 / 4$ do salário mínimo. É um benefício individual, não vitalício e intransferível. O BPC reconhece a pessoa com deficiência como sendo aquela cuja deficiência a incapacita para a vida independente e para o trabalho. Este benefício constitui-se de uma transferência de renda, de caráter não contributivo, e que não pode ser acumulado com outro benefício no âmbito da Seguridade Social, com exceção da assistência médica (MDS, 2007).

11. Este caso remete aos estudos de Paula Sandrine Machado (2008), ao descrever etnograficamente o caso de uma criança intersex atendida no Hospital de Clínicas de Porto Alegre (HCPA). Esta criança apresentava má-formação óssea, o que a incapacitaria de ter uma vida sexual no futuro, e, por isso, por decisão médica, ela não foi "cirurgiada". Assim, a intersexualidade deixou de ser uma questão primária para o gerenciamento sociomédico.

12. Machado (2014) problematiza as nomenclaturas e suas implicações regulatórias no campo da interesexualidade no "Consenso de Chicago", que traz o termo "Desordens/Anomalias do Desenvolvimento Sexual".

${ }^{13 .}$ As cirurgias de redesignação sexual são realizadas em quatro hospitais no Brasil, sendo um deles o Hospital de Clínicas de Porto Alegre (HCPA), que conta com o Programa de Transtorno de Identidade de Gênero (PROTIG).

14. Sabemos que não existe uma congruência entre as lutas dos diferentes movimentos feministas, mas que todos buscam a equidade de gênero, apesar de suas diferenças epistemológicas e políticas. Quando nos referimos aos estudos feministas e queer abordamos uma política pós-identitária. Queer pode ser traduzido do inglês por "estranho", talvez ridículo, excêntrico, raro, extraordinário. Esta expressão também se constitui na forma pejorativa com que são designados gays, bichas, veados, sapatões, etc. na língua inglesa. Insultos que tem a força de uma invocação repetida, que ecoam e reiteram posições de sujeitos, conferindo um lugar discriminado e abjeto àqueles a quem é dirigido (Butler, 2013). Os estudos feministas e queer assumem essa postura e passam a ocupar um movimento de luta, por (e para) não ocupar uma identidade cristalizada, a qual pode se tornar cúmplice do próprio sistema contra o qual eles pretendem se insurgir. Assim, os/as teóricos/as queer sugerem uma teoria e uma política inspiradas no pós-estruturalismo francês, dirigindo sua crítica à hegemonia heterossexual e à binaridade homossexual/heterossexual, compreendidas como categorias que organizam as práticas sociais, o conhecimento e as relações entre os sujeitos (Louro, 2001).

15. No estado do Rio Grande do Sul, por meio do Decreto oㅜ 49122 de 17 de maio de 2012 , foi instituída a Carteira de Nome Social para Travestis e Transexuais no Estado do Rio Grande do Sul. A Prefeitura de Porto Alegre (Prefeitura Municipal de Porto Alegre, 2013), inclusive, dispõe sobre o reconhecimento e uso do nome social para pessoas travestis e transexuais em todas as unidades municipais de saúde.

16. Nomes sociais: são nomes de tratamento pelos quais os sujeitos se identificam, conforme sua identidade de gênero. "Identidade de gênero" se refere ao gênero com o qual uma pessoa se identifica, independentemente do sexo a ela atribuído no nascimento - o qual geralmente ocupa os polos feminino/masculino. Difere da orientação sexual, a qual diz respeito ao sexo pelo qual uma pessoa se sente atraída, emocional, sexual e/ou afetivamente (Corrêa \& Muntarbhorn, 2006).

17. A intersetorialidade nas políticas públicas passou a ser uma ação focada na busca da promoção de produtos sociais em comum entre instituições governamentais e a sociedade civil. Assim, a relação entre os diferentes setores deve ser um eixo das políticas publicas para abordar os problemas sociais (Nascimento, 2010).

Priscila Pavan Detoni, Doutora em Psicologia Social e Institucional pela Universidade Federal do Rio Grande do Sul - UFRGS, é Professora Adjunta na Universidade do Vale do Taquari

(Univates). Endereço para correspondência: Rua General Bento Martins, 542/806 Centro Histórico - Porto Alegre - RS, CEP:90010-080. Email: ppavandetoni@gmail.com

Paula Sandrine Machado, Doutora em Antropologia Social pela Universidade Federal do Rio Grande do Sul- UFRGS, é Professora

Titular na Universidade Federal do Rio Grande do Sul - UFRGS. Email:machadops@gmail.com

Henrique Caetano Nardi, Doutor em Sociologia pela Universidade Federal do Rio Grande do Sul - UFRGS, Pós-Doutor pelas EHESS-Paris, UCM- Espanha, UNAM- México, UQAM- Montréal, é Professor Titular na Universidade Federal do Rio Grande do Sul - UFRGS. Email: hcnardi@gmail.com

Recebido em 30.jun.18 Revisado em 08.out.19 Aceito em 13.dez.19 